\title{
Enhanced Mineralization on Electrically Polarized Hydroxyapatite Ceramics in Culture Medium
}

\author{
Masataka OHGAKI, Satoshi NAKAMURA, Toshinori OKURA* and Kimihiro YAMASHITA \\ Institute of Biomaterials and Bioengineering, Tokyo Medical and Dental University, 2-3-10, Kanda-surugadai, Chiyoda-ku, Tokyo $101-0062$ \\ *Department of Applied Chemistry Faculty of Engineering, Kogakuin University, 1-24-2, Nishishinjuku, Shinjuku-ku, Tokyo $163-8677$
}

\author{
ポーリングアパタイトセラミックスにおける細胞培養液からの固体析出の促進 \\ 大柿真毅 $\cdot$ 中村 聡·大倉利典* $\cdot$ 山下仁大 \\ 東京医科歯科大学生体材料工学研究所, 101-0062 東京都千代田区神田駿河台 2-3-10 \\ *工学院大学工学部, 163-8677 東京都新宿区西新宿 1-24-2
}

\begin{abstract}
Growth enhancement of the bone-like layer on electrically polarized hydroxyapatite was investigated. Dense hydroxyapatite ceramics were electrically polarized in a de field. For estimation of the bone-like grown layer on the polarized hydroxyapatite ceramic surfaces, polarized specimens were immersed not only in a simulated body fluid (SBF) with the inorganic ion-concentrations equal to those of human blood plasma, but also in minimum essential medium (MEM), and in MEM supplemented with $10 \%$ foetal bovine serum. After several days of immersion, the grown crystal layers were observed by scanning electron microscopy, and analyzed by $\mathrm{X}$-ray diffraction and IR spectroscopy. As a result, the bone-like hydroxyapatite crystals grew rapidly on the negatively polarized surface, while the growth was restricted on the positively polarized surface both in SBF and MEM. The morphology of the grown layers on the polarized surface was different among the immersion fluids. The growth enhancement of the bone-like layer on the polarized HAp was demonstrated in multiple ions based on inorganic and organic groups. It was considered that the charged surfaces of the polarized HAp ceramics accelerated the growth of the bone-like layer on the negatively polarized surface, but was inhibited on the positively polarized surface. [Received September 12, 2000; Accepted October 11, 2000]
\end{abstract}

Key-words : Hydroxyapatite, Electrical polarization, Bone-like grown layer, Mineralization, Biological activity

\section{Introduction}

Hydroxyapatite (HAp, $\left.\mathrm{Ca}_{10}\left(\mathrm{PO}_{4}\right)_{6}(\mathrm{OH})_{2}\right)$ is the main component of bone and tooth minerals. Numerous studies in the field of implantable calcium phosphate biomaterials have produced important results concerning both the biocompatibility and ability to stimulate tissue formation. ${ }^{1)-3)}$ Synthesized HAp is a highly biocompatible ceramic, which has potential use in a variety of oral, maxillofacial, and orthopedic applications. Since HAp ceramics are specifically used in hard tissue implantations, and continuing advances in the studies of the growth and deposition of bone-like layers are of great importance in the biomaterial field.

We have recently discovered that polarized HAp has an outstanding effect on the bone-like layer; acceleration and deceleration of the growth of the bone-like layer takes place on the surface of the electrically polarized HAp in simulated body fluid.4)-8) We expect that the polarization effect will initiate novel bioactivation in response to the demands of medical, dental, and scientific applications. In the present paper, we demonstrated enhancements of the bone-like grown layers on electrically polarized hydroxyapatite ceramics.

\section{Experimental procedure}

\subsection{Materials}

The HAp ceramics were obtained by sintering the HAp powders at $1250^{\circ} \mathrm{C}$ for $2 \mathrm{~h}$ under flowing steam. ${ }^{6)}$ The obtained HAp ceramics were characterized by X-ray diffraction (XRD), infrared spectroscopy (IR), and scanning electron microscopy (SEM).

\subsection{Method}

The specimens were sandwiched between platinum electrode plates, heated to $300^{\circ} \mathrm{C}$ in air, and electrically polarized in a dc field of $100 \mathrm{~V} / \mathrm{mm}$ for $2 \mathrm{~h}$. The samples were then cooled to room temperature while being polarized. For the polarized HAp, a negatively polarized surface and a positively polarized surface were denoted as the N-surface and P-surface, respectively (Fig. 1). The surfaces of the specimens without polarization were signified as the $\mathrm{O}$-surface.

Enhancement of the bone-like grown layers and the morphology were demonstrated in vitro. Body fluids contain not only inorganic compounds but also organic compounds such as amino acids, vitamins, and proteins, which have significant roles during bone formation and bone-layer deposition on hard tissue in a living organism. The electrically polarized HAp ceramics were immersed in the following media: (1) $1.5 \mathrm{SBF}$ (simulated body fluid) ${ }^{9}$ ) having 1.5 times the inorganic ion concentrations equal to those of human blood plasma at $\mathrm{pH} 7.25$ and $36.5^{\circ} \mathrm{C}$, (2) $\alpha$-minimum essential medium $(\alpha-\mathrm{MEM})$ having organic constituents of amino acids and vitamins, and (3) $\alpha$-MEM supplemented with $10 \%$ foetal bovine serum (FBS) having additional phases of proteins at $37^{\circ} \mathrm{C}$ (Fig. 1). After several days of immersion, the grown crystal layers were observed by SEM, and analyzed by XRD and IR.

\section{Results and discussion}

The HAp ceramics used in this study were identified as pure HAp by XRD. The IR analysis indicated no reduction of the hydroxide ions in HAp, which are the ions that allow HAp polarization. ${ }^{11)}$ Figure 2 shows SEM photographs of the N-, O-, and P-surface of HAp ceramic after a $1 \mathrm{~d}$ immersion in $1.5 \mathrm{SBF}$, compared to the HAp ceramic surface before immersion in the medium. Grain boundaries were clearly observed on the surface of the HAp ceramics before immersion in the medium. It was observed that the bone-like grown layer covered the $\mathrm{N}$-surface of the HAp (Fig. $2\left(\mathrm{a}_{1}\right)$ ) immersed in SBF. The crystals grown on the P-surface were less than those on the $\mathrm{O}$-surface, because the grain bounda- 

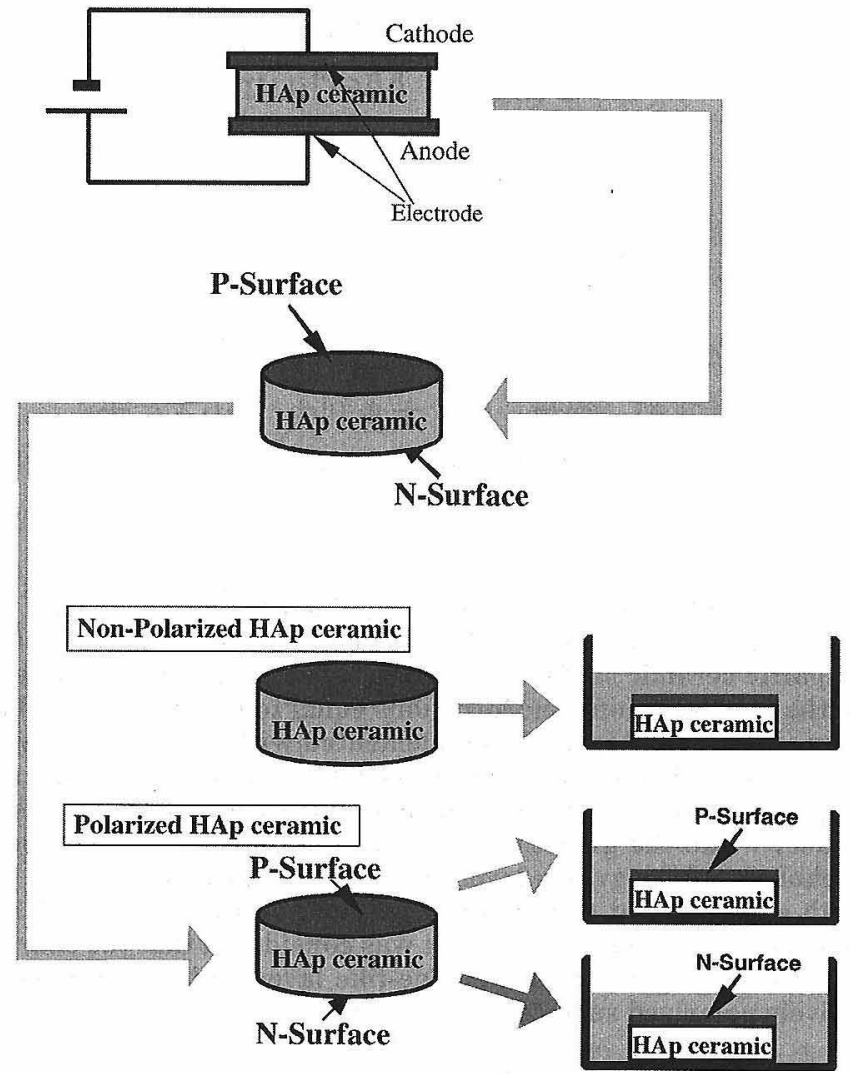

Fig. 1. Schematic representation of electrode configurations to $\mathrm{N}$ - and P-surfaces for polarization, and the sample arrangement for polarization and immersion in simulated body fluid.

ries of the HAp surface significantly appeared on the P-surface (Fig. $2\left(c_{1}\right)$ ). Thus, the growth of the bone-like layer was restrained on the $\mathrm{P}$-surface. On the $\mathrm{O}$-surface, the grown crystals were partly deposited on the surface (Fig. 2 $\left.\left(b_{1}\right)\right)$. Results of the SEM observations on the polarized HAp surfaces revealed that the growth of the bone-like layer was accelerated on the $\mathrm{N}$-surface, whereas the growth was reduced on the P-surface. It was particularly striking that the polarized surface affected the bone-like grown layer after only a $1 \mathrm{~d}$ immersion in SBF. These results agree with the previous results for substantiating the acceleration of the bone-like crystal growths on the HAp films mentioned in previous studies. ${ }^{12-14)}$ The grown crystal layers also covered the $\mathrm{N}$-surface after being immersed in $\alpha$-MEM with and without serum (Figs. $2\left(\mathrm{a}_{2}\right)$ and $\left(\mathrm{a}_{3}\right)$ ). The grain boundaries of HAp ceramics were apparent on the P-surface in Fig. 2( $\left.c_{2}\right)$, and the growth rate of the formed layers on the $\mathrm{P}$-surface was less than that on the $\mathrm{O}$ - and $\mathrm{N}$-surfaces. After immersion in every medium, the layer growths were accelerated on the $\mathrm{N}$-surface, but retarded on the P-surface. It was considered that the $\mathrm{N}$-surface attracted cations, calcium ions in this case, and increased the rate of the local HAp nucleation. It was postulated that the aligned charges of the substrate surface accelerated the growth of the bone-like layer on the $\mathrm{N}$-surface, but reduced it on the P-surface, due to the reorientation of the dipole moments or movement of lattice hydroxide ions ${ }^{11)}$ in the HAp structure. The mode of crystal formation on the HAp ceramics was different in the different immersion media (Fig. 2). The organic molecules, such as amino acids and proteins included in the serum, are considered to be a great help in the formation of bone-layers in living organisms. Surface charges built up on the HAp ceramics enhanced not only the bone-like layer formation but also the deposition of organic molecules from the immersion medium.

Figure 3 shows SEM photographs of the polarized HAp ceramic surfaces after a $7 \mathrm{~d}$ immersion in the culture media. On every polarized surface immersed in SBF, and $\alpha$-MEM supplemented with and without FBS, the mineralization of the bone-like layers was accelerated on the $\mathrm{N}$-surface, but retarded on the P-surface. After the $7 \mathrm{~d}$ immersion in SBF as shown in Fig. $3\left(a_{1}, b_{1}\right.$, and $\left.c_{1}\right)$, the acceleration effect of the bone-like grown layer on $\mathrm{N}$-surface was significantly observed. After immersion in the $\alpha$-MEM supplemented with and without FBS, on the other hand, the grown crystals on the $\mathrm{N}$ - and $\mathrm{O}$-surfaces took the form of not layers but particles (Fig. $3\left(a_{3}, b_{3}, a_{2}\right.$, and $\left.b_{2}\right)$ ). These coated layers of particles were caused by the competitive and concerted deposition between inorganic ions, amino acids, vitamins, and proteins in the media. The chemical substances in the medium, such as inorganic and organic ions, amino acids, and proteins, have same chance to deposit on the HAp surface. However, the ions are repulsed or attracted by the electrical charges on the HAp surface. In the competitive and concerted reactions of ionic deposition, a $\mathrm{Ca}^{2+}$ ion has a significant role in bone-like crystal nucleation. The organic materials such as the amino acids, vitamins, and proteins, on the other hand, have been considered to have important roles in the formation of the bone-like layers near the living bone. Thus, enhancements of the growth of the bone-like layer on the electrically polarized HAp were demonstrated using multiple ions consisting of inorganic and organic groups.

The polarization effect on the growth of the bone-like layer, as revealed in this study, can also take place in living organisms. In this study, the solidification of the bone-like layer from a pseudo-body fluid was demonstrated with respect 


\section{Before soaking in media}

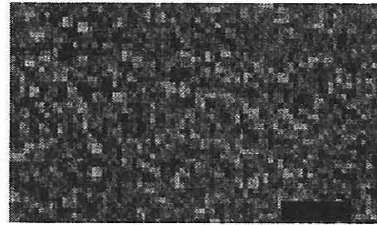

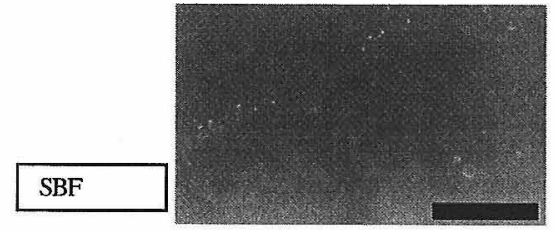

$\left(a_{1}\right)$

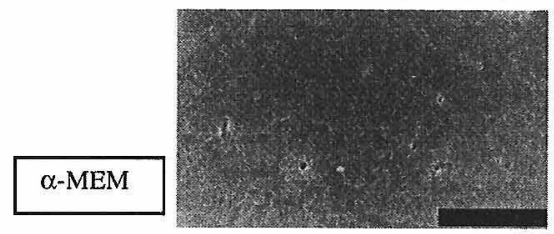

$\left(a_{2}\right)$

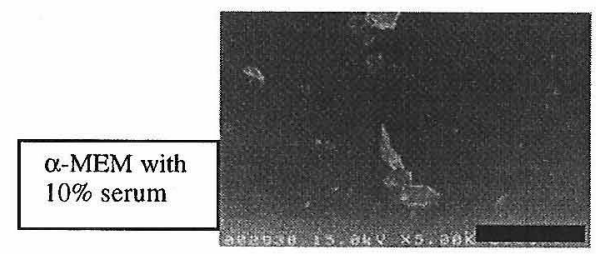

$\left(a_{3}\right)$

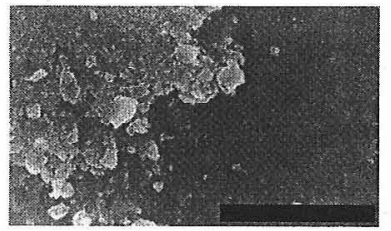

$\left(b_{1}\right)$

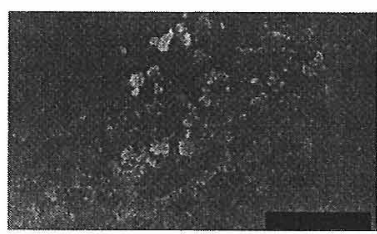

$\left(b_{2}\right)$

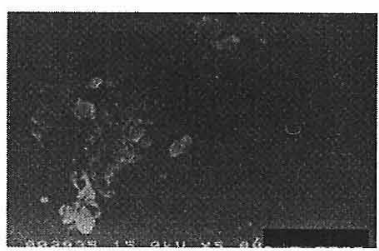

$\left(b_{3}\right)$

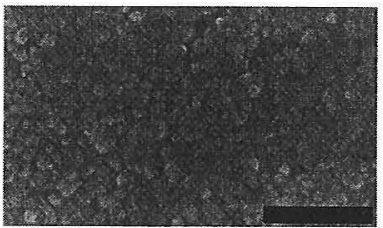

$\left(c_{1}\right)$

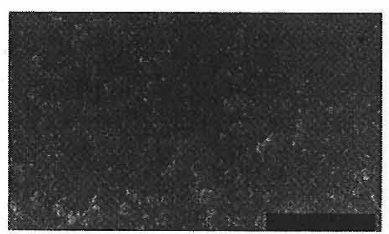

$\left(c_{2}\right)$

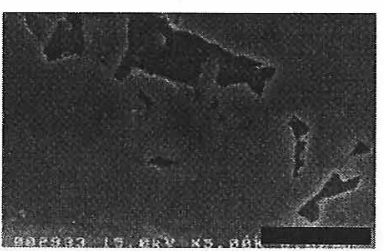

$\left(c_{3}\right)$

\section{$6 \mu \mathrm{m}$}

Fig. 2. SEM photographs of N- (a), O- (b), and P-surface (c) of HAp ceramic after 1 d immersion in SBF $\left(a_{1}, b_{1}, c_{1}\right), \alpha-M E M\left(a_{2}, b_{2}, c_{2}\right)$, and $\alpha$-MEM supplemented with $10 \%$ serum $\left(a_{3}, b_{3}, c_{3}\right)$.

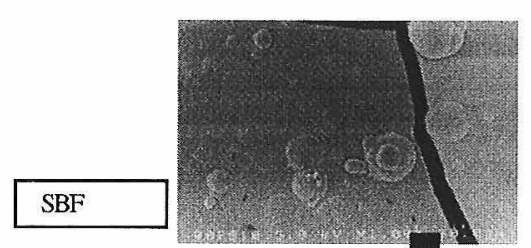

$\left(a_{1}\right)$

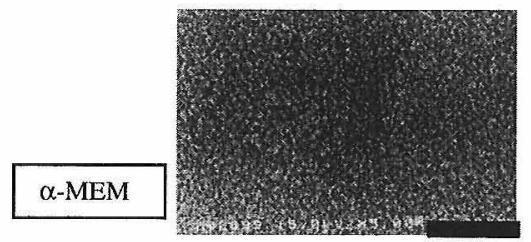

$\left(a_{2}\right)$

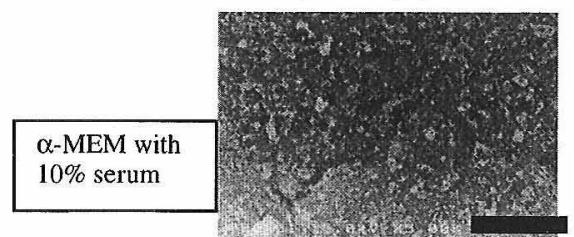

$\left(a_{3}\right)$

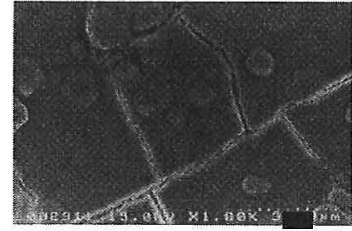

$\left(b_{1}\right)$

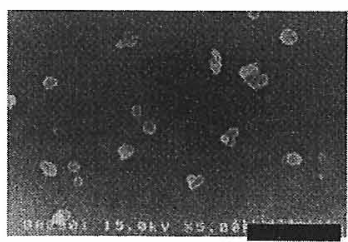

$\left(\mathrm{b}_{2}\right)$

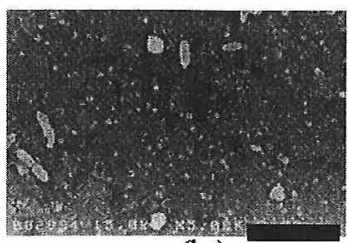

$\left(b_{3}\right)$

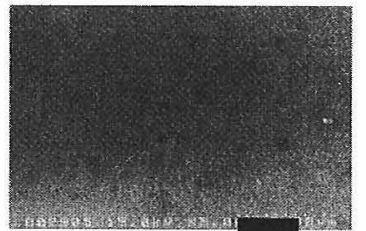

$\left(\mathbf{c}_{1}\right)$

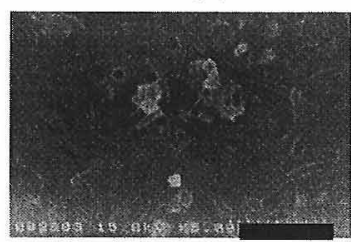

$\left(c_{2}\right)$

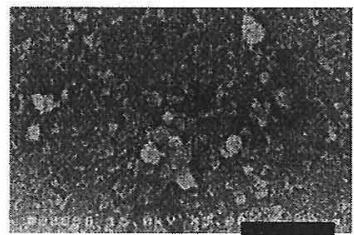

$\left(c_{3}\right)$

Fig. 3. SEM photographs of N- (a), O- (b), and P-surface (c) of HAp ceramic after 7 d immersion in SBF $\left(a_{1}, b_{1}, c_{1}\right), \alpha-M E M\left(a_{2}, b_{2}, c_{2}\right)$, and $\alpha$-MEM supplemented with $10 \%$ serum $\left(a_{3}, b_{3}, c_{3}\right)$. 
to the surface charge effect on polarized HAp ceramics, and the polarization effect is expected to be used for many applications especially in the implantable biomaterial fields.

(This work was partly supported by Grants-in-Aid for Scientific Research (A) No. 10305047, and (C) No. 11650855 from the Ministry of Education, Science, Sports and Culture of Japan.)

Acknowledgments The Kazuchika Okura Memorial Foundation and Inamori Foundation are gratefully acknowledged. We thank Miss Ayako Ishide for her assistance with the experiments.

\section{References}

1) M. Ohgaki and K. Yamashita, Phos. Res. Bulle., 8, 37-42 (1998)

2) C. T. Klein, A. A. Driessen, K. de Groot and A. van den Hooff, J. Biomed. Mater. Res., 17, 769-84 (1983).

3) H. W. Denissen, K. de Groot, P. Ch. Makkes, A. van den Hooff and P. J. Klopper, J. Biomed. Mater. Res., 14, 713-21 (1980).

4) K. de Groot, R. Geesink, C. T. Klein and P. Serekain, J. Biomed Mater. Res., 21, 1375-81 (1987).
5) Y. Kuroyama, H. Aoki, M. Higashikata, K. Yoshizawa, S. Nakamura, M. Ohgaki and M. Akao, J. Jpn. Soc. Dent. Mater. Dev., 12, 528-34 (1993).

6) K. Yamashita, N. Oikawa and T. Umegaki, Chem. Mater., 8 , 2697-700 (1996)

7). K. Yamashita, T. Yagi and T. Umegaki, Phos. Res. Bull., 6, 123-26 (1996)

8) E. Yonehara, K. Yamashita and T. Umegaki, Phos. Res. Bull., 6, 301-04 (1996).

9) K. Hata, T. Kokubo, T. Nakamura and T. Yamamoto, J. Am. Ceram. Soc., 78, 1049-53 (1995).

10) H. Kodama, Y. Amagai, H. Sudo, S. Kasai and S. Yamamoto, Jpn. J. Oral Biol., 23, 899-901 (1981).

11) K. Yamashita, et al. to be published.

12) K. Yamashita, N. Oikawa and T. Umegaki, Proc. 2nd Int'1 Meetings Pac. Rim. Ceram. Soc., Australia (1999) pp. 209-12.

13) M. Ohgaki, J. Hamagami, T. Umegaki and K. Yamashita, Bioceramics, 11, 493-96 (1998).

14) J. Hamagami, D. Kokubu, T. Umegaki and K. Yamashita, Bioceramics, 11, 219-22 (1998). 